\title{
TRAMONTANE: UMA VERDADE INALCANÇÁVEL
}

Natalia Nahas Carneiro Maia Calfat ${ }^{1}$

TRAMONTANE

Drama (Líbano, França, Qatar e Emirados Árabes Unidos)

105 minutos, 2015. Rebus Film Production e Abbout Productions

Direção e roteiro: Vatche Boulghourjian

Produção: Caroline Oliveira e Georges Schoucair

Co-produção: Le Petit Bureau (Gabrielle Dumon)

Música: Cynthia Zaven

Elenco: Barakat Jabbour, Julia Kassar, Toufic Barakat, Michel Adabashi,

Nadim Khodr, Georges Diab, Odette Makhlouf, Raymond Haddouni.

Tramontane conta a história de Rabih Malek (Barakat Jabbour), um jovem cego que vive em uma pequena aldeia montanhosa no interior do Líbano. Rabih frequenta uma escola para cegos, onde também faz parte do coro e toca diversos instrumentos. 0 músico e seu conjunto são convidados para um concerto na Europa, e quando Rabih dá entrada na solicitação de seu passaporte, descobre que seus documentos são falsos. Rabih pede então a sua mãe, Samar Malek (Julia Kassar), ajuda para encontrar seus registros de nascimento. Mas estes tampouco são encontrados. É então que uma primeira mentira de sua mãe logo se segue: que sua certidão de nascimento foi perdida durante a guerra. No Líbano, não possuir uma certidão de nascimento não é tão incomum, vez que muitos registros oficiais foram perdidos durante as guerras - sobre tudo a civil entre 1975 e 1990. A revelação sobre as origens do protagonista vem em pequenos toques, entregue relutantemente por sua mãe, que parece ter se contentado todos estes anos com informações aproximadas sobre as origens do filho. Quando o hospital informa não possuir nenhum vestígio do nascimento em seus registros e quando Rabih solicita um exame de sangue, Samar confessa ser incapaz de fazer o teste para estabelecer a relação de filiação entre ambos. Onde e em que circunstâncias Rabih nasceu e/ou foi colocado para adoção (e por quem) são temas de grande debate e incerteza no decorrer do longa metragem.

\footnotetext{
${ }^{1}$ Natalia Nahas Carneiro Maia Calfat é doutoranda e mestre em Ciência Política pela Universidade de São Paulo (2017), pós-graduada em Política e Relações Internacionais pela Escola de Sociologia e Política de São Paulo (2013) e bacharel em Ciências Sociais pela Universidade de São Paulo (2007). É membro integrante do Grupo de Trabalho sobre Oriente Médio e Mundo Muçulmano da Universidade de São Paulo (FFLCH-LEA) desde 2009. Atualmente é diretora de Relações Nacionais do ICARABE, Instituto da Cultura Árabe. A autora atua nas áreas de Relações Internacionais e Política Internacional relativas à Paz, Defesa e Segurança, Análise de Conjuntura, Terrorismo, Conflitos Internacionais, pós-colonialismo, Oriente Médio e Mundo Muçulmano (curriculum lattes: http://lattes.cnpq.br/3406753169328881 e-mail: nnahascalfat@usp.br).
} 
A mãe Samar então esclarece que a criança foi encontrada e trazida por seu tio Hisham (Toufic Barakat), ainda quando bebê, durante uma patrulha militar em uma aldeia no Sul destruída durante a guerra. Samar não é a verdadeira mãe de Rabih e Hisham teria salvado a criança de uma zona de guerra depois da morte de sua verdadeira família. Obstinadamente, Rabih se propõe a investigar seu passado viajando pelo Líbano de norte a sul. No entanto, a viagem subsequente de Rabih para sua suposta aldeia natal espessa o enredo, já que a cidade nunca entrou em contato com qualquer forma de conflito, e nenhuma criança nunca foi relatada como desaparecida. A aldeia onde Rabih teria nascido nunca foi, de fato, destruída, porque nunca existiu; assim como o casal armênio que teria morrido num táxi bombardeado, abandonando-o ao seu destino; ou como o orfanato armênio que o teria acolhido. Rabih também vai em busca dos velhos irmãos de armas que serviram com seu tio, que misteriosamente desaparece ao longo da trama, durante a guerra. 0 ano de seu nascimento, 1988, é o único fato conhecido; e, embora o filme não o especifique, nos remete a quarta e última fase da guerra civil do Líbano, no momento da "guerra dos campos", uma intensificação dos conflitos político-sectários e inter-regionais no país. ${ }^{2}$

0 filme, primeiro longa metragem escrito e dirigido por Vatche Boulghourjian, foi exibido no Brasil na 40a Mostra Internacional de Cinema de São Paulo em 2016. Foi produzido por Georges Schoucair e pela brasileira estabelecida em Nova Iorque, Caroline Oliveira, da Abbout Productions, em co-produção com o Le Petit Bureau. Em 2016 Tramontane ganhou o 22ำ Prêmio Grand Rail D'Or do Festival de Cannes e menção especial no Festival de Cinema Pula. Também ganhou o prêmio de melhor filme de ficção no 18ํㅜ Festival Internacional de Cinema de Bratislava e Julia Kassar ganhou o prêmio Muhr de melhor atriz no Festival Internacional de Cinema de Dubai em 2016. Adicionalmente, o longa foi nomeado para o grande prêmio no Bilbao Festival Internacional de Documentários e Curtas-metragens, e para os prêmios Câmera de Ouro e Grande Prêmio da Semana de Críticos do Festival de Cinema de Cannes de 2016.

\footnotetext{
${ }^{2}$ Frequentemente descrita como uma disputa sectária entre cristãos e muçulmanos, a guerra civil libanesa foi fruto de um cruzamento cada vez mais intenso entre a alienação socioeconômica de determinados setores e queixas confessionais. Este cenário foi insuflado pela presença de guerrilhas palestinas no Líbano, acelerando o desequilíbrio do delicado arranjo político confessional do país. Como explica Maksoud et al. (2017), exacerbada por diversas intervenções estrangeiras, a guerra civil libanesa desembocou numa complicada síntese de conflitos inter e intracomunitários caracterizados pela crescente fragmentação das milícias associadas a cada uma das comunidades sectárias. O Líbano entre 1985 e 1989 descendeu em uma "sociedade de guerra" à medida que as várias milícias se envolveram cada vez mais com contrabando, extorsão e tráfico de armas e drogas e começaram a perder sua legitimidade populista. (MAKSOUD et al. 2017). Este período de desintegração cristalizou-se com o declínio de muitas das instituições remanescentes do país; e, em 1987, o colapso da libra libanesa - que tinha demonstrado uma surpreendente resiliência durante os primeiros dez anos da guerra - levou a um período de profunda dificuldade econômica e inflação. Em setembro de 1989, após meses de intensa violência, Michel Aoun como primeiro-ministro interino aceitou um cessar-fogo promovido por um comitê tripartite formado pelos líderes da Argélia, Marrocos e Arábia Saudita. Em Outubro de 1989 o Acordo de Taif foi assinado, encerrando 15 anos de guerra civil que deixou centenas de milhares de mortos e mais de 1.000 .000 de deslocados. (MAKSOUD et al. 2017).
} 
A saga de Rabih é retratada em Tramontane através de suas viagens por toda a parte rural do Líbano em busca de um registro de seu nascimento, acompanhando todas as pistas possíveis que lhe são dadas por sua mãe, seu tio Hisham e por aqueles que encontra ao longo do caminho. Ele conhece pessoas nas franjas mais distantes da sociedade que contam as suas próprias histórias, abrem mais perguntas e dão pequenas pistas a Rabih sobre sua identidade. Mas Rabih navega por uma rede de desinformação, já que cada um com quem encontra fabrica uma história diferente para se proteger do passado e encobrir as atrocidades da guerra [TRAMONTANE (RABIH), s/d]. Ao cabo, são microcosmos brevemente apresentados por Boulghourjian e deixados ali, propositadamente sem resolução. Estes pequenos núcleos oferecem "personalidades encapsuladas" nos termos de Jay Weissberg (2016), ao mesmo tempo em que concedem um sentido mais profundo do trauma causado pela guerra civil.

Ao procurar o cerne de sua própria existência, Rabih se depara com o vazio e com a incerteza. E encontra uma nação que ao mesmo tempo em que é incapaz de contar a verdadeira narrativa do protagonista, é também incapaz de contar a sua própria narrativa como nação [TRAMONTANE (RABIH), s/d]. Não existe uma única e coesa história nacional do conflito, cada comunidade possui a sua própria narrativa, e é isto que Rabih encontra pelo caminho a partir de sua perspectiva individual. (BOULGHOURJIAN, 2017). Nas palavras de Jay Weissberg, Rabih representa a intertextualidade de uma nação cegada pela guerra e por mentiras contínuas que impedem a cura nacional. (WEISSBERG, 2016). Conforme também escreve Lemercier, o longa é "uma descida no passado nebuloso de um país que mantém muito mais mentiras e surpresas estocadas, onde a verdade e a falsificação se borram e onde a única testemunha dos acontecimentos é a terra debaixo dos pés". (LEMERCIER, 2016).

No intento de transmitir tal nebulosidade, para o diretor Vatche Boulghourjian (2016) o uso da luz era fundamental, assim como a subexposição das tomadas, tornandoas mais escuras. Isto não somente porque o protagonista Rabih é cego e para conferir ao público esta sensação, mas também devido aos momentos tematicamente escuros na narrativa, em termos de ausência de informação e do senso de perda do qual Rabih é vítima, duplamente. A escolha de Barakat Jabbour como protagonista refletiu o desejo de Boulghourjian de encontrar um ator cego para desempenhar o papel - não um ator com visão tentando capturar as complexidades e sutilezas da existência diária com a cegueira. Cego desde o nascimento e um prodígio musical, Barakat realmente personificou o papel principal. Boulghourjian também buscou escolher especificamente locais bastante remotos no Líbano, não muito comuns no cinema, e paisagens variadas, de secas a exuberantes, de costas a montanhas. A paisagem no filme é quase como um personagem, argumenta o roteirista (BOULGHOURJIAN 2016). O país é também um personagem, igualmente belo, igualmente cego. 
Conforme escreve Thomas Sotinel, "a verdade é talvez encontrada em textos menos explícitos que os livros de história, como nas partituras. Essa inflexão da reflexão histórica em direção à emoção estética é acentuada pela sensualidade das paisagens libanesas filmadas durante toda a viagem do protagonista". (SOTINEL, 2016). Outras belas e grandiosas tomadas, conforme aponta Elisabeth Franck-Dumas (2016), mostram que "os cegos e a nação são igualmente incapazes de apreender os estigmas de sua história". 0 plano no qual um amigo guia a mão de Rabih em um mapa do Líbano, e onde ele coloca pontos de referência em relevo, e as imagens das casas que parecem eternamente em construção "são partes de uma sequência musical que expressam, convincentemente, o que ainda permanece sendo a herança nacional". (FRANCK-DUMAS, 2016). De forma estética e musical, quase apolítica, Boulghourjian é capaz de apelar para a verdade mais sensorial que histórica na busca pela identidade.

Como bem escreve Boyd van Hoeij (2016), Boulghourjian nunca funde propriamente ao longo do filme os aspectos pessoais da viagem de Rabih, em busca de sua ascendência, e os aspectos políticos de uma nação que tenta avançar ignorando seu passado. Boulghourjian não faz os aspectos pessoais e políticos avançarem de forma simultânea, e em nenhum momento o filme se torna abertamente político (HOEIJ, 2016). E muito provavelmente esta tenha sido sua intenção. Ao contrário, prefere se concentrar no impacto que o conflito teve sobre as famílias em todo o espectro libanês e como elas subsequentemente ignoraram ou acobertaram o que aconteceu no país.

Alguns críticos, é verdade, podem apontar a metáfora de Rabih representando um país cego como clichê simplório e gratuito; podendo inclusive atribuir este uso à imaturidade do cineasta, haja vista ser este seu primeiro longa metragem. E é evidente que para o espectador leigo, um manuseio mais claro e mais detalhado sobre a política e sobre como eventos do passado informam o presente e reverberam em vidas individuais teria sido útil para compreensão das várias subtramas que se apresentam ao longo de Tramontane (ainda que sem se desenrolarem). Como resultado, o espectador, como escreve Boyd van Hoeij, "obtém como fato principal que a guerra é confusa e que uma porção de coisas ruins aconteceu". Ou como em Franck-Dumas (2016) obtém-se um resultado impreciso, em que a violência, encarnada pelo tio de Rabih, Hisham, um soldado envolvido em práticas escusas durante a guerra, é somente sugerida. Mas para o libanês enfadado das crueldades da guerra vivida de 1975 à 1990 e que ainda guarda seus cadáveres e esqueletos no armário, sem saber como se livrar dos mesmos, a carência do elemento político e sectário talvez seja providencial.

Igualmente, é possível que tenha sido intenção do diretor não esclarecer exatamente as origens de Rabih, na medida em que os próprios registros da guerra estão encobertos e suscitam temores e tristezas. Como bem escreve Thomas Sotinel, "quarenta anos após o 
início da guerra civil, e enquanto ela ainda ameaça retornar, o Líbano não consegue ver seu passado, e todos os esforços para iluminá-lo são, no melhor dos casos, devotados à indiferença ou, na pior das hipóteses, ao fracasso". (SOTINEL, 2016). Conforme escreve Elisabeth Franck-Dumas, nos é revelado em uma troca de frases que o tio de Rabih conhecia uma de suas vítimas antes do conflito, e a trama sugere que de alguma forma este estivesse envolvido na morte de seus pais. Mas este envolvimento não é totalmente esclarecido. E é neste momento que, nas palavras da autora, "ouvimos uma definição terrível e justa do que constitui uma guerra civil: os vizinhos, os amigos, repentinamente se entregando ao pior. É pouco, diante da terrível complexidade do conflito libanês, que vemos todos os dias como poderia inflamar novamente. Mas também eleva o filme a um vasto horizonte de universalidade." (FRANCK-DUMAS , 2016). De certo modo, é como se o elemento político débil em Tramontane humanizasse a trama e seus personagens, conferindo então à produção maior alcance.

Barakat Jabbour como cantor e percussionista vive um musicalmente lindo e silencioso drama íntimo, mas tematicamente forte e devastador. Intercalado por cenas de canto e música, pelo violino, pelo alaúde, pelo daff e pelo derbake, na medida em que Rabih perde todas as suas certezas sobre sua história e suas origens, vai paulatinamente se desprendendo de seu senso de pertencimento a uma determinada família e comunidade. Rabih então se depara com a necessidade de redefinição de sua identidade. 0 próprio diretor e roteirista Vatche afirmou que o filme, pessoalmente, foi "nada menos que uma jornada espiritual, de autodescoberta e de consciência" (BOULGHOURJIAN \& OLIVEIRA, 2016). Boulghourjian (2016) explica que a produção é sobre um homem cego em busca de suas origens, mas também sobre o efeito da narrativa sobre nós, neste caso, a narrativa que literalmente leva o protagonista de lugar a lugar. Tramontane "é sobre a história de um país e seus efeitos na memória de seus habitantes, sobre como a história afeta vidas privadas e como a memória informa a ação no presente." (BOULGHOURJIAN \& OLIVEIRA, 2016).

Rabih ouve todas estas narrativas, que podem ser verdade ou mentira, ou parcialmente corretas, escolhe partes das narrativas e constrói a sua própria. (BOULGHOURJIAN 2016). Trata-se de um conto edificado por inúmeras mentiras e uma verdade elusiva. 0 protagonista continua na dúvida, desconhecendo exatamente o que aconteceu em seu passado, preso na angústia em que "todos mentem, ninguém conta a verdade" sobre o que o tio teria feito durante a guerra. É uma busca existencial nublada por uma teia de segredos e realidades fabricadas, refletindo um país onde a guerra civil deixou cicatrizes profundas que foram cuidadosamente encobertas. É também aqui a saga de um país em dificuldade de definir sua narrativa sobre o passado e que tenta alcançar uma verdade que talvez seja inexequível, ou múltipla. De quebra, a produção conta com belíssimos interlúdios musicais penetrados por mensagens subliminares nas letras amargamente cantadas por Rabih como "Uma resposta, mesmo se você quiser me culpar, não me poupe, envie-me uma resposta, um alívio"; "Eles 
foram embora e nunca voltaram, deixando meu coração em pedaços"; "Se você não sabe o seu próprio nome, como você pode saber quem você é?”. (LEMERCIER, 2016). Neste momento a belíssima música de abertura "Eb'tely gawab" (Envie-me uma Carta), se transforma em um grito por ajuda, por uma resposta. (FAHIM, 2016).

Tramontane, que de acordo com o dicionário Oxford vem do latim transmontanus ou além das montanhas, se refere aquele relativo ou vivendo do outro lado das montanhas, especialmente os Alpes como vistos da Itália, da Estrela Polar Italiana Tramontana, vento do norte. 0 termo pode referir-se de forma mais generalista a qualquer coisa vista como estrangeira, estranha, ou mesmo bárbara. O músico cego em sua saga representa uma metáfora do próprio Líbano, na sua luta desesperada por deixar as feridas da guerra civil no passado ao mesmo tempo em que permanece em busca de sua própria identidade, entre passado e futuro. 0 esforço de Rabih, que canta pedindo resposta aos ventos e vilarejos além das montanhas e alívio às suas angústias e incertezas, é em direção a um necessário autoconhecimento, mas que exige, ao mesmo tempo, que ele seja paciente em sua tristeza. Tramontane é um drama humano, sem dúvida, que ressoa a própria falta de sentido com a qual presente, passado e futuro nos brindam e nos deixam órfãos de lógica e explicação - ainda que não vivamos o drama de Rabih. E que nos relembra que talvez ninguém tenha segurança sobre o passado ou sobre a verdade. Não seria qualquer passado uma verdade inalcançável que nos impõe um abatido conformismo? Não seria qualquer verdade uma composição de múltiplas narrativas concorrentes e sobrepostas?

Mas Tramontane é também um drama de um país que ainda não soube verdadeiramente superar as lutas político-sectárias vividas durante a guerra civil e que ainda é visto como um país extremamente dividido que precisa recorrer à representação política de suas diferentes seitas e ao empoderamento de líderes religiosos. Líderes exclusivistas estes que ajudam a perpetuar um sistema sectário na medida em que mantêm as divisões entre os cidadãos e os confina a vidas ligadas à comunidade. (HENLEY, 2016). Isto termina por inibir a integração social entre as diversas comunidades religiosas e por suprimir a representação da diversidade ao invés de melhorá-la. Talvez a praticamente ausência do elemento religioso em Tramontane, tão cara à realidade confessional libanesa, signifique que esta forma de representação já não mais tenha representatividade política entre os libaneses. Boulghourjian ele mesmo afirma que as divisões da guerra permanecem, mas não podem ser reduzidas aos seus componentes religiosos ou ideológicos. Ao borrar as fronteiras sectárias, recusando-se a identificar os personagens por sua religião ou seita, busca ilustrar a complexidade da temática e como o efeito pós-guerra sobre a realidade atual libanesa é composto por múltiplas camadas (FAHIM, 2016).

Em outro sentido, o desconhecimento do público sobre como Rabih lidará com seu colapso identitário e com a perda do senso de pertencimento comunal talvez reflita a própria incerteza vivida ainda hoje pelo país desde o fim da guerra civil, que remanesce 


\section{resenha de filme}

se debatendo entre o espírito de pertencimento comunitário tradicional e o senso de cidadania laica. Rabih e o país dos cedros compartilham a mesma necessidade e crise existencial: a de redefinição do eu e entendimento de quem são, a qual conjunto de valores e referências pertencem, e qual será o caminho a ser trilhado a partir desta jornada de auto conhecimento - tão trágica quanto potencialmente frutífera. Inspirado no livro de John M. Hull, Touching the Rock: An Experience of Blindness (1992), Boulghourjian cita o autor: "é preciso recriar-se a si mesmo ou ser destruído". (BOULGHOURJIAN, 2017) 


\section{resenha de filme}

\section{Referências}

BOULGHOURJIAN, Vatche. Interview Vatche Boulghourjian TRAMONTANE. La Semaine de la Critique. 20 maio 2016. Disponível em: <https://www.youtube.com/ watch?v=aWSkIbXKg80>. Acesso em 06 jan. 2017.

. 'Tramontane': Light, shadow and Lebanon's painful history. France 24. 07

fev. 2017. Disponível em: <http://www.france24.com/en/20170207-culture-vatcheboulghourjian-tramontane-cinema-movie-lebanon-music-identity-war>. Acesso em 24 fev. 2017.

BOULGHOURJIAN, Vatche \& OLIVEIRA, Caroline. Tramontane's Journey from Lebanon to Cannes. 17 maio 2016. Sundance Institute. Disponível em: <http://www.sundance.org/ blogs/from-the-labs/tramontane-journey-from-lebanon-to-cannes>. Acesso em 06 jan. 2017.

FAHIM, Joseph. New Lebanese Civil War Film a Standout. Middle East Institute. 22 nov. 2016. Disponível em: <http://www.mei.edu/content/article/new-lebanese-civil-warfilm-standout>. Acesso em 24 fev. 2017.

FRANCK-DUMAS, Elisabeth. Tramontane Liban a Perte de Vue. Liberation. 27 maio 2016. Disponível em: <http://www.abboutproductions.com/latest-news.php?id=280>. Acesso em 06 jan. 2017.

HENLEY, Alexander D. M. Religious Authority and Sectarianism in Lebanon. Carnegie Endowment for International Peace. 16 dec. 2016. Disponível em: <http:// carnegieendowment.org/2016/12/16/religious-authority-and-sectarianism-inlebanon-pub-66487>. Acesso em 06 jan. 2017.

HOEIJ, Boyd van. 'Tramontane' ('Rabih'): Cannes Review. The Hollywood Reporter. 17 maio 2016. Disponível em: <http://www.hollywoodreporter.com/review/tramontane-rabihcannes-review-894376>. Acesso em 06 jan. 2017.

HULL, John M. Touching the rock: An experience of blindness. Vintage Books. 1992.

LEMERCIER, Fabien. Tramontane: “A special case". CANNES 2016 Critics' Week. Cineuropa. 17 maio 2016. Disponível em: <http://www.cineuropa.org/ nw.aspx?t=newsdetail\&l=en\&did=309472>. Acesso em 06 jan. 2017.

MAKSOUD, Clovis F.; OCHSENWALD, William; BARNETT Richard \& KINGSTON Paul. Lebanon. History (Lebanon After Independence). Encyclopædia Britannica. 6 jan. 2017. Disponível em: <https://global.britannica.com/place/Lebanon/Government-andsociety\#ref386586>. Acesso em: 09 jan. 2017.

SOTINEL, Thomas. «Tramontane » : un musicien non-voyant comme métaphore du Liban. Le Monde. 27 maio 2016. Disponível em: <http://www.abboutproductions.com/latestnews.php?id=277>. Acesso em 06 jan. 2017.

TRAMONTANE (RABIH). A Film by Vatche Boulghourjian. Tramontane Project. s/d. Disponível em: <http://www.tramontaneproject.com/>. Acesso em 06 jan. 2017. 


\section{resenha de filme}

WEISSBERG, Jay. Film Review: 'Tramontane'. Variety. 18 maio 2016. Disponível em: <http://variety.com/2016/film/reviews/tramontane-review-1201778288/>. Acesso em 06 jan. 2017.

Texto recebido em: 11 de Janeiro de 2017

Aprovado em: 24 de Março de 2017 